\title{
Correction of Iron Deficient Yellowing of Huangguogan by Different Application of Chelated Iron under Different Mulching Material
} \author{
Bo Xiong ${ }^{1}$, Honghong Deng ${ }^{1}$, Ling Liao ${ }^{1}$, Guochao Sun ${ }^{2}$, and Zhihui Wang ${ }^{2}$ * \\ ${ }^{1}$ College of Horticulture, Sichuan Agricultural University, 611130 Chengdu, Sichuan, China \\ ${ }^{2}$ Institute of Pomology \& Olericulture, Sichuan Agricultural University, 611130 Chengdu, Sichuan, China \\ ${ }^{3}$ College of Environmental, Sichuan Agricultural University, 611130 Chengdu, Sichuan, China
}

Zhaofang Chen ${ }^{1}$, Liting Wen ${ }^{1}$, Liancong Yang ${ }^{3}$, Youting Yang ${ }^{1}$, Liping Tan ${ }^{1}$, Xiaojia Wang ${ }^{1}$, Shengjia Huang ${ }^{1}$, Xia Qiu ${ }^{1}$,

\begin{abstract}
In this experiment, the asbestos chinensis was selected as the experimental material, and it was treated with black mulch, straw mulch, horticultural cloth mulch and river sand mulch, and compared with the control group to study the correction of iron deficiency yellowing of the leaves of Huangguogan. The results showed that the application of chelated iron under different mulching materials can significantly improve the photosynthesis index and leaf fluorescence characteristics of leaves, and correct the problem of iron deficiency yellowing of yellow fruit orange. The degree of correction of leaf iron deficiency yellowing by root-chelating iron was different under different mulching materials. In general, the correction effect of river sand mulch treatment was the most obvious, and the correction effect of black mulch was the worst. It was economical, practical, simple and convenient to correct the iron deficiency yellowing of the yellow fruit by mulching the material, and it had certain promotion value.
\end{abstract}

\section{Introduction}

Huangguogan was a hybrid variety of Citrus in Rutaceae family. It originated from Shimian County, Ya'an City, Sichuan Province, and was a local late ripening characteristic fruit. It has three characteristics of the flowers and fruit exist at the same time, high yield and late ripening [1]. It has become the key industry of agricultural economic development in Shimian County. In recent years, it has been found through field research that local Huangguogan appeared chlorosis at the top of the new shoots from March to April, and the leaves lost luster, shrinkage, browning and cracking of the leaf margins over time [2]. It showed that the yellow leaf disease of Huangguogan in this area was caused by iron deficiency in the tree. Therefore, improving and controlling iron-deficiency yellowing of Huangguogan was of great significance to promote the development of the local Huangguogan industry.

Mulching farmland with materials such as sand, pebbles, corn grass, leaves and animal manure, was an agricultural technique with a long history of improving soil conditions and promoting crop growth [3]. With the development of science and technology, land mulch technology has become one of the indispensable cultivation techniques in agricultural production. For Huangguogan plants with rhizosphere fertilization and mulching with different materials, there were not too many relevant studies on the corrective research of its iron-deficiency yellowing. Orchard surface mulch was different surface mulch materials had different effects on soil fertility and water and heat conditions [4]. Therefore, through applying iron fertilizer to the roots under different mulching materials, this study explored the best mulching materials for correcting iron-deficiency yellowing and promoted them to provide effective treatment of iron-deficiency yellowing diseases in the actual production of Huangguogan reference.

\section{Materials and Methods}

\subsection{Experimental materials}

Eight-years Huangguogan with the same tree vigor, management level, yellowing degree and yellowing rate was selected as the experimental material, and the material was planted in the Huangguogan planting base in Shimian County. The experimental fertilizer was highefficiency EDDHA chelated iron, EDDHA-Fe was $6.0 \%$ and it was suitable for all kinds of fruit trees.

\subsection{Experimental design}

The mulching materials were mulch, straw, horticultural cloth and river sand, and they were marked as A, B, C, and $\mathrm{D}$, respectively. The blank without mulching was used as a control (CK). With a single plant as the plot, a total of 15 test materials were selected. The test treatment was shown in Table 1.

\footnotetext{
* Corresponding author: Zhihui Wang@,wangzhihui318@126.com
} 
Table 1. Treatment of rhizosphere fertilization with different mulching materials.

\begin{tabular}{|c|c|}
\hline Treatment & Experimental method \\
\hline A & black mulch \\
\hline B & straw mulch \\
\hline C & horticultural cloth mulch \\
\hline D & river sand mulch \\
\hline CK & no coverage \\
\hline
\end{tabular}

\subsection{Experimental methods}

After the fertilization treatment, the determination was carried out in mid-May, mid-September, and midJanuary of the following year, and they were marked as $\mathrm{T} 1, \mathrm{~T} 2$ and $\mathrm{T} 3$, respectively.

\subsubsection{Leaf chlorophyll content}

The relative content of leaf chlorophyll was measured with SPAD-502 chlorophyll meter.

\subsubsection{Photosynthetic parameters}

The net photosynthetic rate $(\mathrm{Pn})$, transpiration rate $(\mathrm{Tr})$, stomatal conductance (Gs), intercellular $\mathrm{CO}_{2}$ concentration $(\mathrm{Ci})$ and other photosynthetic parameters of Huangguogan were measured with a portable photosynthetic instrument (Li-6400), and the instantaneous water use of leaves Efficiency (WUE) was calculated [5]. The setting parameters were: the light intensity was $1400 \mu \mathrm{moL} \cdot \mathrm{m}^{-2} \cdot \mathrm{s}^{-1}$, the $\mathrm{CO}_{2}$ concentration was $400 \mu \mathrm{moL} \cdot \mathrm{moL}^{-1}$, and the temperature was $25^{\circ} \mathrm{C}$.

\subsubsection{Chlorophyll fluorescence characteristics}

The leaf chlorophyll fluorescence parameters were measured with a portable photosynthetic instrument (Li6400) [5]. By measuring the chlorophyll fluorescence parameters, the maximum photochemical efficiency (Fv/Fm), photochemical quenching coefficient (qP) and non-photochemical quenching coefficient (NPQ) of Photosystem II (PSII) can be calculated.

\section{Results}

\subsection{Chlorophyll content in leaves}

The chlorophyll content of leaves increased slightly first, and then decreased significantly (Table 2). The chlorophyll content of leaves under different mulching materials was significantly higher than that of CK. Among the different mulching materials, the treatment effect of river sand mulching was significantly higher than that of other mulching materials, followed by horticultural cloth mulching. There was no significant difference in chlorophyll content between the black mulching and straw mulching treatments at the T1 and T3 periods, while the chlorophyll content under the straw mulching at the T2 period was significantly higher than that of the black mulching.

Table 2. The content of chlorophyll in leaves after applying chelated iron to roots under different mulching materials.

\begin{tabular}{|c|c|c|c|}
\hline \multirow{2}{*}{ Treatment } & \multicolumn{3}{|c|}{ Leaf chlorophyll content $/ \mathrm{mg} \cdot \mathrm{g}^{-1}$} \\
\cline { 2 - 4 } & $\mathrm{T} 1$ & $\mathrm{~T} 2$ & $\mathrm{~T} 3$ \\
\hline A & $1.74 \pm 0.015 \mathrm{c}$ & $2.04 \pm 0.017 \mathrm{~d}$ & $0.74 \pm 0.015 \mathrm{c}$ \\
\hline B & $1.76 \pm 0.012 \mathrm{c}$ & $2.48 \pm 0.021 \mathrm{c}$ & $0.76 \pm 0.012 \mathrm{c}$ \\
\hline C & $1.81 \pm 0.009 \mathrm{~b}$ & $2.66 \pm 0.029 \mathrm{~b}$ & $0.81 \pm 0.009 \mathrm{~b}$ \\
\hline D & $1.86 \pm 0.015 \mathrm{a}$ & $2.88 \pm 0.015 \mathrm{a}$ & $0.86 \pm 0.015 \mathrm{a}$ \\
\hline CK & $1.25 \pm 0.019 \mathrm{~d}$ & $1.89 \pm 0.011 \mathrm{e}$ & $0.65 \pm 0.015 \mathrm{~d}$ \\
\hline
\end{tabular}

Note: Different lowercase letters within columns indicate significant differences $(P<0.05)$ between different treatments. The same below.

\subsection{Determination of photosynthetic parameters}

\subsubsection{Determination of leaf net photosynthetic rate and leaf stomatal conductance}

The Pn of leaves with different treatments increased first and then decreased (Table 3). Compared with CK, different mulching materials treatments can significantly increase the Pn of leaves. The Pn of leaves under river sand mulching increased the most, and was significantly higher than that of other mulching treatments. The Pn of leaves under black mulching increased the least, and it was significantly lower than other mulching treatments.

Table 3. Net photosynthetic rate of leaves after applying chelated iron to roots under different mulching materials.

\begin{tabular}{|c|c|c|c|}
\hline \multirow{2}{*}{ Treatment } & \multicolumn{3}{|c|}{$\mathrm{Pn} /\left(\mu \mathrm{moL} \cdot \mathrm{m}^{-2} \cdot \mathrm{s}^{-1}\right)$} \\
\cline { 2 - 4 } & $\mathrm{T} 1$ & $\mathrm{~T} 2$ & $\mathrm{~T} 3$ \\
\hline A & $1.49 \pm 0.024 \mathrm{~d}$ & $3.96 \pm 0.019 \mathrm{~d}$ & $1.13 \pm 0.032 \mathrm{~d}$ \\
\hline B & $3.17 \pm 0.026 \mathrm{~b}$ & $6.24 \pm 0.020 \mathrm{~b}$ & $2.87 \pm 0.011 \mathrm{~b}$ \\
\hline C & $2.94 \pm 0.015 \mathrm{c}$ & $5.32 \pm 0.021 \mathrm{c}$ & $2.34 \pm 0.015 \mathrm{c}$ \\
\hline D & $3.61 \pm 0.034 \mathrm{a}$ & $7.21 \pm 0.009 \mathrm{a}$ & $3.19 \pm 0.012 \mathrm{a}$ \\
\hline CK & $1.05 \pm 0.023 \mathrm{e}$ & $3.31 \pm 0.010 \mathrm{e}$ & $1.01 \pm 0.009 \mathrm{e}$ \\
\hline
\end{tabular}

After treatment with different mulching materials, the Cs of the blades can be significantly increase, and the Cs of the blades first increased and then decreased significantly (Table 4). In the T1 and T2 periods, CK had the lowest Gs, which was significantly lower than that of the other mulching material treatments. In the T1 period, the Cs under the river sand mulch was the largest, which was significantly higher than that of other mulching treatments; while in the T2 and T3 periods, the Cs under the river sand mulch and the horticultural cloth mulch was the highest, and there were no significant differences. 
Table 4. Stomatal conductance of leaves after applying chelated iron to roots under different mulching materials.

\begin{tabular}{|c|c|c|c|}
\hline \multirow{2}{*}{ Treatment } & \multicolumn{3}{|c|}{$\mathrm{Gs} /\left(\mu \mathrm{moL} \cdot \mathrm{m}^{-2} \cdot \mathrm{s}^{-1}\right)$} \\
\cline { 2 - 4 } & $\mathrm{T} 1$ & $\mathrm{~T} 2$ & $\mathrm{~T} 3$ \\
\hline A & $0.127 \pm 0.002 \mathrm{~d}$ & $0.195 \pm 0.002 \mathrm{c}$ & $0.016 \pm 0.001 \mathrm{~b}$ \\
\hline B & $0.155 \pm 0.002 \mathrm{c}$ & $0.214 \pm 0.002 \mathrm{~b}$ & $0.023 \pm 0.001 \mathrm{~b}$ \\
\hline C & $0.170 \pm 0.001 \mathrm{~b}$ & $0.235 \pm 0.002 \mathrm{a}$ & $0.032 \pm 0.001 \mathrm{a}$ \\
\hline D & $0.176 \pm 0.001 \mathrm{a}$ & $0.239 \pm 0.001 \mathrm{a}$ & $0.035 \pm 0.001 \mathrm{a}$ \\
\hline CK & $0.113 \pm 0.001 \mathrm{e}$ & $0.173 \pm 0.001 \mathrm{~d}$ & $0.019 \pm 0.003 \mathrm{~b}$ \\
\hline
\end{tabular}

\subsubsection{Determination of intercellular $\mathrm{CO}_{2}$ concentration, transpiration rate and instantaneous water use efficiency in leaf}

Treatments with different mulching materials can significantly increase the $\mathrm{Ci}$ concentration of leaves, and its concentration first increased and then decreased (Table 5). During the $\mathrm{T} 1$ and $\mathrm{T} 3$ periods, the $\mathrm{Ci}$ of leaves was the highest under the river sand mulching treatment, which was significantly higher than the other treatments. In the $\mathrm{T} 2$ period, the $\mathrm{Ci}$ of leaves under the straw mulching treatment was the highest.

Table 5. Leaf intercellular $\mathrm{CO}_{2}$ concentration after applying chelated iron to roots under different mulching materials.

\begin{tabular}{|c|c|c|c|}
\hline \multirow{2}{*}{ Treatment } & \multicolumn{3}{|c|}{$\mathrm{Ci} /\left(\mathrm{mmoL} \cdot \mathrm{m}^{-2} \cdot \mathrm{s}^{-1}\right)$} \\
\cline { 2 - 4 } & $\mathrm{T} 1$ & $\mathrm{~T} 2$ & $\mathrm{~T} 3$ \\
\hline A & $257.00 \pm 0.11 \mathrm{c}$ & $308.59 \pm 0.16 \mathrm{~d}$ & $221.70 \pm 0.19 \mathrm{~d}$ \\
\hline B & $287.48 \pm 0.26 \mathrm{~b}$ & $334.70 \pm 0.71 \mathrm{a}$ & $247.68 \pm 0.14 \mathrm{c}$ \\
\hline C & $251.72 \pm 0.13 \mathrm{~d}$ & $311.79 \pm 0.52 \mathrm{c}$ & $251.72 \pm 0.13 \mathrm{~b}$ \\
\hline D & $296.42 \pm 0.26 \mathrm{a}$ & $321.47 \pm 0.08 \mathrm{~b}$ & $278.19 \pm 0.13 \mathrm{a}$ \\
\hline CK & $241.19 \pm 0.51 \mathrm{e}$ & $293.88 \pm 0.26 \mathrm{e}$ & $210.83 \pm 0.20 \mathrm{e}$ \\
\hline
\end{tabular}

Treatments with different mulching materials can significantly increase $\mathrm{Tr}$, which first increased and then decreased significantly (Table 6). In each period, the $\mathrm{Tr}$ under the river sand mulching treatment was the highest, and it was significantly higher than the other treatments. The $\mathrm{Tr}$ increased slightly under the black mulching, which was significantly lower than the other treatments.

Table 6. Leaf transpiration rate after applying chelated iron to roots under different mulching materials.

\begin{tabular}{|c|c|c|c|}
\hline \multirow{2}{*}{ Treatment } & \multicolumn{3}{|c|}{$\operatorname{Tr} /\left(\mu \mathrm{moL} \cdot \mathrm{m}^{-2} \cdot \mathrm{s}^{-1}\right)$} \\
\cline { 2 - 4 } & $\mathrm{T} 1$ & $\mathrm{~T} 2$ & $\mathrm{~T} 3$ \\
\hline A & $1.02 \pm 0.020 \mathrm{~d}$ & $1.15 \pm 0.012 \mathrm{~d}$ & $0.57 \pm 0.003 \mathrm{~d}$ \\
\hline B & $1.14 \pm 0.007 \mathrm{c}$ & $1.24 \pm 0.007 \mathrm{c}$ & $0.65 \pm 0.023 \mathrm{c}$ \\
\hline C & $1.26 \pm 0.009 \mathrm{~b}$ & $1.35 \pm 0.008 \mathrm{~b}$ & $0.76 \pm 0.018 \mathrm{~b}$ \\
\hline D & $1.45 \pm 0.005 \mathrm{a}$ & $1.55 \pm 0.009 \mathrm{a}$ & $0.86 \pm 0.012 \mathrm{a}$ \\
\hline CK & $0.78 \pm 0.003 \mathrm{e}$ & $1.07 \pm 0.015 \mathrm{e}$ & $0.46 \pm 0.009 \mathrm{e}$ \\
\hline
\end{tabular}

Treatment of different mulching materials can significantly improve the WUE of leaves, and it first increased and then decreased (Table 7). The WUE of leaves in the straw mulching treatment was the highest, and it was significantly higher than the other mulching treatments; followed by the river sand mulching and horticultural cloth mulching treatment. In the T1 and T2 periods, the WUE of leaves in CK was the lowest. In the T3 period, the WUE of leaves under the mulching treatment and $\mathrm{CK}$ were 2.18 and $1.97 \mathrm{mmoL} \cdot \mathrm{moL}^{-1}$, respectively, and there was no significant difference.

Table 7. Leaf instantaneous water use efficiency after applying chelated iron to roots under different mulching materials.

\begin{tabular}{|c|c|c|c|}
\hline \multirow{2}{*}{ Treatment } & \multicolumn{3}{|c|}{ WUE/(mmoL $\left.\cdot \mathrm{moL}^{-1}\right)$} \\
\cline { 2 - 4 } & T1 & T2 & T3 \\
\hline A & $1.47 \pm 0.007 \mathrm{~d}$ & $3.43 \pm 0.049 \mathrm{~d}$ & $2.18 \pm 0.023 \mathrm{~d}$ \\
\hline B & $2.79 \pm 0.014 \mathrm{a}$ & $5.05 \pm 0.015 \mathrm{a}$ & $4.40 \pm 0.165 \mathrm{a}$ \\
\hline C & $2.34 \pm 0.021 \mathrm{c}$ & $3.92 \pm 0.042 \mathrm{c}$ & $3.10 \pm 0.090 \mathrm{c}$ \\
\hline D & $2.50 \pm 0.019 \mathrm{~b}$ & $4.64 \pm 0.032 \mathrm{~b}$ & $3.73 \pm 0.045 \mathrm{~b}$ \\
\hline CK & $1.34 \pm 0.032 \mathrm{e}$ & $3.09 \pm 0.034 \mathrm{e}$ & $1.97 \pm 0.045 \mathrm{~d}$ \\
\hline
\end{tabular}

\subsection{Chlorophyll fluorescence characteristics}

Treatment of different mulching materials can significantly increase the Fv/Fm of PSII (Table 8). The $\mathrm{Fv} / \mathrm{Fm}$ under river sand mulching treatment was the highest, which was significantly higher than other mulching treatments. In the $\mathrm{T} 1$ period, the $\mathrm{Fv} / \mathrm{Fm}$ under different mulching materials showed significant differences. In the $\mathrm{T} 2$ and $\mathrm{T} 3$ periods, there was no significant difference in the $\mathrm{Fv} / \mathrm{Fm}$ between the straw mulching and the horticultural cloth mulching treatments, but they were both significantly higher than the black mulching treatment.

Table 8. Maximum photochemical efficiency of Photosystem II (PSII).

\begin{tabular}{|c|c|c|c|}
\hline \multirow{2}{*}{ Treatment } & \multicolumn{3}{|c|}{ Maximum photochemical efficiency (Fv/Fm) } \\
\cline { 2 - 4 } & T1 & T2 & T3 \\
\hline A & $0.41 \pm 0.009 \mathrm{~d}$ & $0.58 \pm 0.003 \mathrm{c}$ & $0.38 \pm 0.009 \mathrm{c}$ \\
\hline B & $0.47 \pm 0.009 \mathrm{c}$ & $0.62 \pm 0.003 \mathrm{~b}$ & $0.43 \pm 0.012 \mathrm{~b}$ \\
\hline C & $0.51 \pm 0.003 \mathrm{~b}$ & $0.63 \pm 0.012 \mathrm{~b}$ & $0.46 \pm 0.023 \mathrm{~b}$ \\
\hline D & $0.58 \pm 0.008 \mathrm{a}$ & $0.70 \pm 0.003 \mathrm{a}$ & $0.52 \pm 0.003 \mathrm{a}$ \\
\hline CK & $0.34 \pm 0.012 \mathrm{e}$ & $0.48 \pm 0.008 \mathrm{~d}$ & $0.27 \pm 0.003 \mathrm{~d}$ \\
\hline
\end{tabular}

Treatment of different mulching materials can significantly increase the qP coefficient of PSII, which first increased and then decreased (Table 9). The qP coefficient of CK was the lowest. There were significant differences in the $\mathrm{qP}$ coefficient of different mulching materials. The qP coefficient under river sand mulch was the highest, followed by horticultural cloth and straw mulch, and the black mulch was the lowest. 
Table 9. Photosystem II (PSII) photochemical quenching coefficient.

\begin{tabular}{|c|c|c|c|}
\hline \multirow{2}{*}{ Treatment } & \multicolumn{3}{|c|}{ Photochemical quenching coefficient (qP) } \\
\cline { 2 - 4 } & $\mathrm{T} 1$ & $\mathrm{~T} 2$ & $\mathrm{~T} 3$ \\
\hline A & $0.42 \pm 0.008 \mathrm{~d}$ & $0.58 \pm 0.011 \mathrm{~d}$ & $0.26 \pm 0.009 \mathrm{~d}$ \\
\hline B & $0.46 \pm 0.017 \mathrm{c}$ & $0.68 \pm 0.012 \mathrm{c}$ & $0.30 \pm 0.007 \mathrm{c}$ \\
\hline C & $0.52 \pm 0.009 \mathrm{~b}$ & $0.77 \pm 0.015 \mathrm{~b}$ & $0.34 \pm 0.015 \mathrm{~b}$ \\
\hline D & $0.58 \pm 0.007 \mathrm{a}$ & $0.84 \pm 0.015 \mathrm{a}$ & $0.39 \pm 0.009 \mathrm{a}$ \\
\hline CK & $0.34 \pm 0.017 \mathrm{e}$ & $0.54 \pm 0.003 \mathrm{e}$ & $0.23 \pm 0.006 \mathrm{e}$ \\
\hline
\end{tabular}

Treatments of different mulching materials can significantly increase the PSII non-photochemical quenching coefficient (NPQ), which first increased and then decreased (Table 10). The NPQ of CK was the lowest. There were significant differences in the NPQ of different mulching materials. The NPQ under river sand mulching were the highest, followed by horticultural cloth and straw mulching, and black mulching the lowest.

Table 10. Photosystem II (PSII) non-photochemical quenching coefficient (NPQ).

\begin{tabular}{|c|c|c|c|}
\hline \multirow{2}{*}{ Treatment } & \multicolumn{3}{|c|}{$\begin{array}{c}\text { Non-photochemical quenching coefficient } \\
\text { (NPQ) }\end{array}$} \\
\cline { 2 - 4 } & $\mathrm{T} 1$ & $\mathrm{~T} 2$ & $\mathrm{~T} 3$ \\
\hline A & $0.43 \pm 0.008 \mathrm{~d}$ & $0.52 \pm 0.012 \mathrm{~d}$ & $0.31 \pm 0.009 \mathrm{~d}$ \\
\hline B & $0.48 \pm 0.017 \mathrm{c}$ & $0.61 \pm 0.012 \mathrm{c}$ & $0.35 \pm 0.007 \mathrm{c}$ \\
\hline C & $0.54 \pm 0.009 \mathrm{~b}$ & $0.70 \pm 0.015 \mathrm{~b}$ & $0.39 \pm 0.014 \mathrm{~b}$ \\
\hline D & $0.60 \pm 0.007 \mathrm{a}$ & $0.77 \pm 0.015 \mathrm{a}$ & $0.44 \pm 0.009 \mathrm{a}$ \\
\hline CK & $0.36 \pm 0.018 \mathrm{e}$ & $0.47 \pm 0.003 \mathrm{e}$ & $0.28 \pm 0.015 \mathrm{e}$ \\
\hline
\end{tabular}

\section{Discussion and Conclusion}

The response of plant photosynthesis to PAR and $\mathrm{Ci}$ changes were important indicators of plant physiology and biochemistry [6]. The growth and development of green plants mainly depended on photosynthesis to fix $\mathrm{CO}_{2}$ to synthesize organic matter. The strength of photosynthesis directly determined the level of biological and economic output. The WUE was an important indicator that coupled plant leaf photosynthesis and water physiological processes. Generally, the higher the efficiency of WUE, the stronger the ability of plants to accumulate dry matter under assimilation. The $\mathrm{Fv} / \mathrm{Fm}$ was an important indicator for judging light suppression.

Some studies have shown that the chlorophyll content and leaf area of the yellowish hybrid orange leaves are significantly lower than the normal Shiranui. Leaf yellowing can significantly reduce leaf chlorophyll and photosynthetic gas exchange parameters, and also significantly reduce $\mathrm{Fv} / \mathrm{Fm}, \mathrm{qP}, \mathrm{NPQ}, \mathrm{Pn}$, and photosynthesis [7]. However, these indicators can be significantly improved by applying chelated iron to the roots under different mulching materials, which indicated that the above treatment had a certain corrective effect on the iron-deficiency yellowing of the leaves of Huangguogan, and can improve the yellowing of the leaves to a certain extent. The results of this experiment showed that the application of chelated iron to roots under different mulching materials can significantly improve leaf photosynthesis and leaf fluorescence characteristics, and correct the irondeficiency yellowing problem of Huangguogan. Generally speaking, river sand mulching had the most obvious correction effect, followed by horticultural cloth and straw mulching, and finally black mulching had the worst correction effect. This test comprehensively evaluated some indicators related to leaf iron-deficiency yellowing, and then found a suitable method for correcting iron-deficiency yellowing. The method of river sand mulching to correct iron-deficiency yellowing was economical and practical.

\section{Acknowledgments}

I would like to give my sincere gratitude to professor Zhihui Wang, my tutor who, provided me with necessary materials, advice of great value and inspiration of new ideas. My heartfelt thanks also to the people who have offered me valuable help.

\section{References}

1. Z.H., Wang, S.F., Liu, Q.Q., Yan. (2011) Investigation of Biological characteristics of Huangguogan in shimian county and comparison of different strains. Northern Horticulture., 14 :20-24.

2. D.H., Wang, T.J., Li. (1991) The selection and breeding of an excellent line of HuangguoganGuiwankan. China Mandarin., 20(3): 3-5.

3. Y.Z., Liu, K.Q., Zhang, G.Q., Wang, Q.X., Li, W.R., Sun, Y., Zhai. (2005) Research progress on dryland agricultural mulching cultivation techniques. Chinese Agricultural Science Bulletin., 21(5): 202205.

4. C., Tu, J., Wang, W.Z., Liu. (2012) Dry farmland soil respiration and its influencing factors under different mulching conditions. Journal of Plant Nutrition and Fertilizer., 18(5): 1107-1114.

5. M.L., Gao, Y., Qi, W.H., Song, H.R., Xu. (2016) Effects of di-n-butyl phthalate and di (2-ethylhexyl) phthalate on the growth, photosynthesis, and chlorophyll fluorescence of wheat seedlings. Chemosphere., 151: 76-83.

6. Z.P., Ye. (2010) Research progress on models of photosynthesis response to light and $\mathrm{CO}_{2}$. Chinese Journal of Plant Ecology., 34(6): 727-740.

7. B., Xiong, Q.Q., Yan, G.C., Shun, X., Qiu, S., Ye, L., Liao, J.Y., Luo, L., Dai, Z.H., Wang. (2017) Effects of Different Yellowing Degrees on the Growth and Photosynthesis of Citrus Seedlings. Journal of Zhejiang Agriculture., 29(9): 1506-1514. 